\title{
Prevalence of trait and state anxiety prior a surgery
}

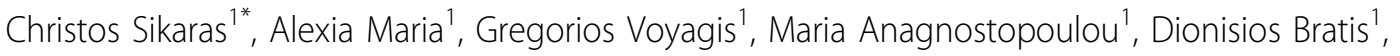 \\ Athanasios Tselebis ${ }^{1}$, Aikaterini Moulou ${ }^{1}$, Konstantinos Toutouzas $^{2}$, Eleni Kiritsi ${ }^{3}$, Christodoulos Stefanadis ${ }^{2}$ \\ From $1^{\text {st }}$ International Congress on Neurobiology and Clinical Psychopharmacology and European \\ Psychiatric Association Conference on Treatment Guidance \\ Thessaloniki, Greece. 19-22 November 2009
}

\section{Background}

It is well known that an operation is undoubtedly a significant factor of anxiety symptoms development [1]. Aim of the study is to investigate the association between the trait and the state anxiety in patients prior a surgery, as well as the association of these psychological features with the ASA classification of the patient physical status, the age and the gender.

\section{Materials and methods}

One hundred and fifty two patients (99 males and 53 females), with ASA I-III and mean age $42.10 \pm 16.01$ years, who were undergoing an operation included in the study. All participants filled out the Spielberger State-Trait Anxiety Inventory (STAI) [2,3] 12 - 15 hours before the operation. The inventory differentiates the state anxiety from the personality's trait anxiety.

\section{Results}

Means of state and trait anxiety were $42.55 \pm 11.30$ and $38.33 \pm 8.01$, respectively, with significant difference (t-test, $\mathrm{p}<0.001)$. Furthermore, a strong correlation was observed between state and trait anxiety (Pearson Correlation, $\mathrm{p}<0.001, \mathrm{r}=0.61$ ). Regarding gender, females had significant higher state and trait anxiety scores (t-test, $\mathrm{p}<0.05)$. In particular, $25.3 \%$ of males had pathological state anxiety scores, whereas the corresponding percentage in females was $45.3 \%$ ( $\mathrm{x} 2$ test, $\mathrm{p}<0.05)$. Younger patients $(18-29$ years old) presented significant higher levels of state and trait anxiety compared with the age groups over 50 years (Anova test, $\mathrm{p}<0.05)$. Considering the ASA physical status of the patient, no statistical difference was observed between stages, as to trait anxiety, although patients with ASA III presented higher scores compared to patients with ASA I and ASA II (Anova test, p > 0.05). However, patients with ASA III presented significant higher state anxiety scores compared to patients with ASA I and ASA II (Anova test $\mathrm{p}<0.05$ ).

\section{Conclusions}

Our findings suggest that younger patients, females and patients with ASA III are more vulnerable to anxiety. Therefore, these factors should be taken into account for the preoperative assessment in order to develop supportive psychological interventions.

\section{Author details}

${ }^{1}$ Sotiria General Hospital of Chest Diseases, Athens, Greece. ${ }^{2}$ Hippokration Hospital, Department of Cardiology, University of Athens, Greece.

${ }^{3}$ Department of Nursing A', Technological Educational Institute of Athens, Greece.

\section{Published: 22 April 2010}

\section{References}

1. Johnston M: Impending surgery. Handbook of life stress, Cognition and Health Fisher S, Reason J 1988, 79-100.

2. Tselebis A, Gournas G, Tzitzanidou G, Panaghiotou A, Ilias I: Anxiety and Depression in Greek nursing and medical personnel. Psychological Reports 2006, 99:93-96.

3. Spielberger CD, Goruch RL, Lushene RE: The state - trait Anxiety Inventory. Palo Alto CA: Consulting Psychologists Press 1970.

doi:10.1186/1744-859X-9-S1-S162

Cite this article as: Sikaras et al:: Prevalence of trait and state anxiety prior a surgery. Annals of General Psychiatry 2010 9(Suppl 1):S162.

${ }^{1}$ Sotiria General Hospital of Chest Diseases, Athens, Greece 